\title{
A survey of chiral hypervalent iodine reagents in asymmetric synthesis
}

\author{
Soumen Ghosh ${ }^{\ddagger}$, Suman Pradhan ${ }^{\ddagger}$ and Indranil Chatterjee ${ }^{*}$
}

\author{
Review \\ Address: \\ Department of Chemistry, Indian Institute of Technology Ropar, \\ Nangal Road, Rupnagar, Punjab 140001, India \\ Email: \\ Indranil Chatterjee* - indranil.chatterjee@iitrpr.ac.in \\ * Corresponding author $\ddagger$ Equal contributors \\ Keywords: \\ alkene functionalization; asymmetric synthesis; hypervalent iodine; \\ organocatalysis; oxidation
}

\author{
Beilstein J. Org. Chem. 2018, 14, 1244-1262. \\ doi:10.3762/bjoc. 14.107 \\ Received: 12 February 2018 \\ Accepted: 02 May 2018 \\ Published: 30 May 2018 \\ This article is part of the Thematic Series "Hypervalent iodine chemistry in \\ organic synthesis". \\ Guest Editor: T. Wirth
}

(C) 2018 Ghosh et al.; licensee Beilstein-Institut.

License and terms: see end of document.

\begin{abstract}
The recent years have witnessed a remarkable growth in the area of chiral hypervalent iodine chemistry. These environmentally friendly, mild and economic reagents have been used in catalytic or stoichiometric amounts as an alternative to transition metals for delivering enantioenriched molecules. Varieties of different chiral reagents and their use for demanding asymmetric transformations have been documented over the last 25 years. This review highlights the contribution of different chiral hypervalent iodine reagents in diverse asymmetric conversions.
\end{abstract}

\section{Introduction}

It is more than one century ago since the discovery of the first hypervalent iodine reagent (HIR) [1] and hypervalent iodine chemistry has started to flourish as one of the important and leading areas in organic synthesis. In recent years many excellent reviews have detailed the bonding, reactivity, synthesis, and uses of hypervalent iodine reagents [2-14]. These compounds feature a unique three-centered four-electron bond [15-20] that renders them valuable and important alternatives to transition-metal chemistry. Over the last 25 years hypervalent iodine reagents have gained growing application due to their reduced toxicity, ready availability and lower costs as replace- ment for transition metals leading to several "metal-free" like chemical transformations.

The ongoing demand of modern synthetic chemistry for the development of catalytic enantioselective $\mathrm{C}-\mathrm{C}$ bond formation reactions turned the attention of the scientific community towards the evolution of new chiral hypervalent iodine reagents. In recent years, many complex synthetic challenges have been successfully addressed by applying these reagents [21,22]. The superior advantage of these reagents lies in their strong electrophilicity and appreciable oxidizing properties. The transformat- 
ions associated with asymmetric induction mainly focused on the asymmetric oxidation and oxidative dearomatization chemistry. Asymmetric difunctionalization of alkenes, $\alpha$-functionalization of carbonyls and also some typical 1,2-aryl rearrangement reactions add further value to this chemistry.

The strategies used for the synthesis of chiral hypervalent iodine reagents include either the introduction of chirality through the attachment of chiral acids or chiral alcohols to the iodine centers by ligand exchange or are achieved by the introduction of axial chirality through the iodoarene backbone. A series of chiral iodine reagents are documented below (Scheme 1). In many cases chiral I(I) reagents get oxidized in situ to the hypervalent I(III) reagents and/or these chiral $\mathrm{I}(\mathrm{III}) / \mathrm{I}(\mathrm{V})$ reagents are used in a catalytic amount in the presence of an external oxidant. The use of catalytic chiral hypervalent iodine reagents in asymmetric catalysis is one of the most challenging ongoing topics and this review will focus on the development of various chiral hypervalent iodine reagents and their application in typical organic transformations.

\section{Review}

\section{Asymmetric oxidation of sulfides}

Pribam was the first to use chiral iodine reagents [23]. After a long time without further developments in this direction, Imamoto et al. introduced a new class of chiral hypervalent iodine reagents $\mathbf{1}$ obtained by the reaction of iodosylbenzene with various derivatives of L-tartaric acid anhydrides in 1986. A promising asymmetric induction was achieved for the oxidation of sulfides $\mathbf{2 3}$ to sulfoxides $\mathbf{2 4}$. This marked the beginning of an era of asymmetric oxidation of sulfides. However, the presence of $C_{2}$ symmetry in the chiral unit is essential to obtain decent enantioselectivity [24]. Later, Kita et al. used chiral tartaric acid derivatives to synthesize chiral I(V) reagents 2 from $\mathrm{PhIO}_{2}$. This represented the first example of the catalytic use of chiral hypervalent reagents in the oxidation of sulfides to sulfoxides with decent enantioselectivities (ees, Scheme 2a). The asymmetric oxidations were examined in $20 \mathrm{~mol} \%$ cetyltrimethylammonium bromide (CTAB) reversed micelles [25]. Interestingly, Varvoglis et al. synthesized another new class of a chiral reagent 3 using (+)-camphor sulfonic acids as the source of chirality [26] which was used by Chen et al. for the oxidation of sulfides to sulfoxides with good yields but with poor enantioselectivity (Scheme 2b) [27]. Later, Zhdankin et al. synthesized different classes of chiral I(V) reagents 4 based on various amino acids as sources of chirality. The oxidation of the readily available 2-iodobenzamides (synthesized from amino acid derivatives) with potassium bromate or Oxone $\left(2 \mathrm{KHSO}_{5} / \mathrm{KHSO}_{4} /\right.$ $\mathrm{K}_{2} \mathrm{SO}_{4}$ ) efficiently delivered the $\mathrm{I}(\mathrm{V})$ reagents 4 (Scheme 2c) $[28,29]$. Although good product yields were obtained for the oxidation of sulfides, the ees were very low.
New classes of chiral hypervalent iodine reagents were obtained by the introduction of chiral alcohols directly to the iodine reagent through ligand exchange. Koser et al. used $(+)$ - or (-)-menthol as a source of chirality during their synthesis of the new chiral iodine reagent 5 [30]. Chiral sulfoxides 24 (having $\mathrm{R}^{1}=p$-Tol, $t$-Bu, $\mathrm{Bn}$ and $\mathrm{R}^{2}=\mathrm{Me}$ ) were obtained for the first time with excellent enantioselectivity (Scheme $2 d$ ). Another class of chiral I(V) reagents 6 was synthesized by Wirth et al. who synthesized the desired compounds through esterification between chiral alcohols and the I(I)-substituted aromatic acids followed by oxidation with dimethyldioxirane (Scheme 2e) [31]. A summary of chiral hypervalent iodine reagents used in the asymmetric oxidation of sulfides is sketched below (Scheme 2).

\section{Asymmetric oxidative dearomatization, alkene functionalization and rearrangement strategy \\ Oxidative dearomatization}

Asymmetric oxidative dearomatizations and the use of dearomatized products to generate chiral complex molecular scaffolds in a short and efficient way is one of the attractive strategies used in chiral hypervalent iodine chemistry. Kita et al. for the first time developed a new chiral I(III) catalyst 7 having a rigid spirocyclic backbone. They applied it for the enantioselective oxidative dearomatization of phenolic derivatives $\mathbf{2 5}$ (spirolactonization) which is known as Kita oxidation to yield spirocyclic compounds $\mathbf{2 6}$ with good enantioselectivity [32]. The indication of an associative mechanism was also confirmed due to an increased enantioselectivity observed in polar solvents. Further, they were able to improve the enantioselectivity by implying steric effects at the ortho/ortho' $(\mathrm{R}=\mathrm{Et}$ in 7) positions of the aromatics (Scheme 3) [33]. The regeneration of the catalyst was achieved by $m$-CPBA converting iodine compound $7^{\prime}$ to chiral catalyst 7 . The authors predicted a plausible mechanism and transition-state model 27 for the formation of the major isomer through the attack of the carboxylic acid group to the ipso position of the naphthol ring from the less sterically hindered $R e$-face of the substrate 25. It is worth mentioning that very recently they have introduced a new kind of binaphthylbased chiral I(III) prereagent 19 with the 8 and $8^{\prime}$ positions of the naphthalene substituents being occupied by iodide. Here they have observed that this chiral hypervalent iodine reagent 19 in the presence of co-oxidant $m$-CBPA is very useful for the dearomatizing spirocyclization of naphthol carboxylic acid [34].

Later Birman et al. reported a new variation of a chiral $\mathrm{I}(\mathrm{V})$ reagent, namely 2-(o-iodoxyphenyl)oxazoline derivative 28 [35]. The reagent was applied to an asymmetric $[4+2]$ Diels-Alder dimerization of phenolic derivatives $\mathbf{2 9}$ to construct tricyclic derivatives $\mathbf{3 0}$ with moderate enantiose- 


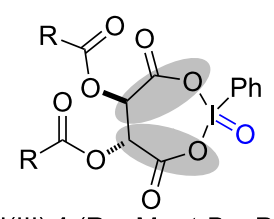

$\mathrm{I}(\mathrm{III}) \mathbf{1}(\mathrm{R}=\mathrm{Me}, t-\mathrm{Bu}, \mathrm{Ph})$

I(V) $2\left(\mathrm{R}=2-\mathrm{OMeC}_{6} \mathrm{H}_{4}\right)$

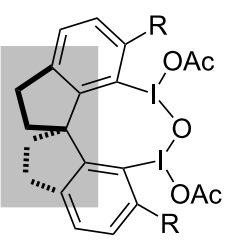

$\mathrm{R}=\mathrm{H}, \mathrm{Et}$ I(III) 7

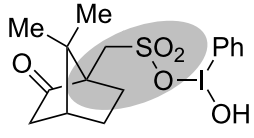

I(III) 3

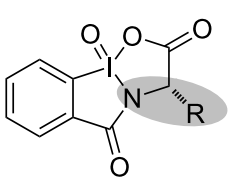

$\mathrm{R}=$ alkyl

I(V) 4<smiles></smiles>

I(III) 5<smiles>[R]OC(=O)c1ccccc1[N+](=O)[O-]</smiles>
chirality from $\mathrm{R}$

$\mathrm{R}=$ alkyl, aryl

I(V) 6

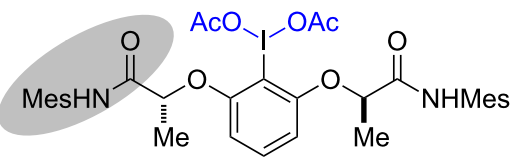

Mes $=$ mesityl

I(III) prereagent $\mathbf{8 a}$ I(III) $\mathbf{8 b}$

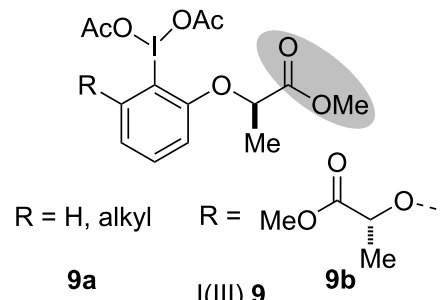

$9 a$

I(III) 9

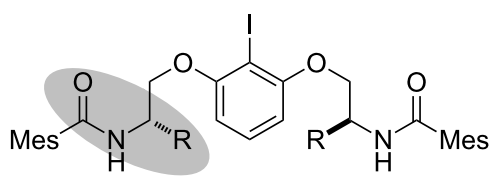

$\mathrm{R}=\mathrm{iPr}, t-\mathrm{Bu}$

I(III) prereagent 11

I(III) prereagent 10<smiles>[R]OC(=O)C([Y4])Oc1cccc(OC([Y6])C(=O)O)c1C(F)(F)F</smiles>

$\mathrm{R}=t-\mathrm{Bu}$

I(III) 13
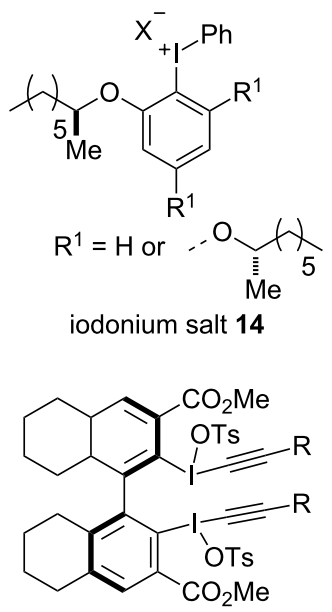

$\mathrm{R}=t-\mathrm{Bu}, \mathrm{TBS}$

I(III) 18

I(III) 15

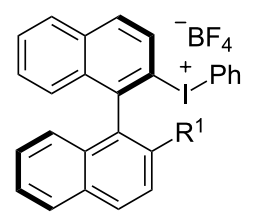

$\mathrm{R}^{1}=\mathrm{H}, \mathrm{Bn}$

iodonium salt 16

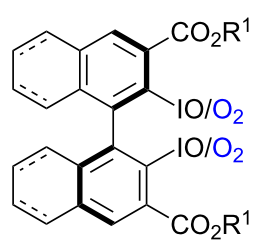

$\mathrm{R}^{1}=\mathrm{H}$ or $\mathrm{Me}$

I(III) 17a and I(V) 17b<smiles>[R]c1ccc2cccc(I)c2c1-c1c([R])ccc2cccc(I)c12</smiles>

$\mathrm{R}=\mathrm{H}, \mathrm{Me}, \mathrm{iPr}$

I(III) prereagent 19

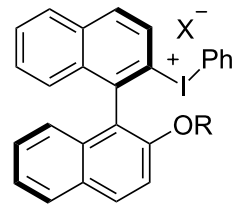

$\mathrm{R}=\mathrm{Me}, \mathrm{Ph}$ $\mathrm{X}=\mathrm{BF}_{4}, \mathrm{BPh}_{4}$

iodonium salt $\mathbf{2 0}$

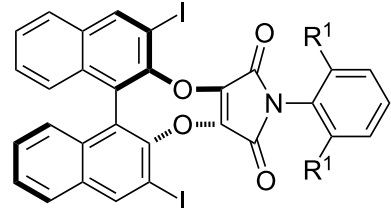

$\mathrm{R}^{1}=$ alkyl, Br, aryl, benzyl alcohol, benzyl ester

I(III) prereagent 21

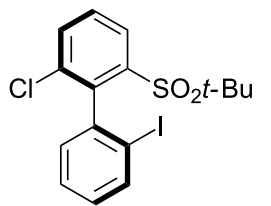

I(III) prereagent 22 


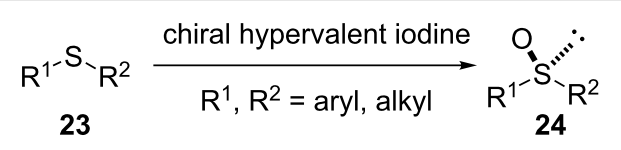

chiral hypervalent iodine from chiral anhydrides and chiral acids

a)<smiles>[R]C(=O)O[C@@H]1C(=O)OP(=O)(c2ccccc2)O[C@H](C(=O)O)[C@@H]1OC([R])=O</smiles>

b)

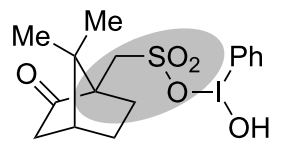

c)<smiles></smiles>

$1(2.0$ equiv) $(\mathrm{R}=\mathrm{Me}, t-\mathrm{Bu}, \mathrm{Ph})$ acetone, rt, $3 \mathrm{~h}$ up to $53 \%$ ee by Imamoto

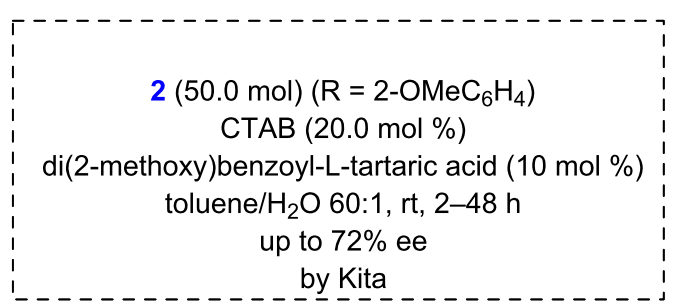

chiral hypervalent iodine from chiral alcohols

d)<smiles>CC1CCC(C(C)C)C(=O)C1</smiles>

Ts $=p$-toluenesulfonyl

1) 5 (1.0 equiv), $\mathrm{CH}_{2} \mathrm{Cl}_{2}$ 2) $\mathrm{NaOH}, \mathrm{H}_{2} \mathrm{O}$

up to $99 \%$ ee (after recrystallization from a diastereomeric mixture followed by hydrolysis) by Koser e)<smiles>[R]OC(=O)c1ccccc1[N+](=O)[O-]</smiles>

chirality from $R$

$\mathrm{R}=$ alkyl, aryl

6 (0.5-1.0 equiv)

$\mathrm{CH}_{3} \mathrm{CN}, 0-50^{\circ} \mathrm{C}$ by Wirth

Scheme 2: Asymmetric oxidation of sulfides by chiral hypervalent iodine reagents.

lectivity (Scheme 4). Although modest ees were obtained, this chiral oxazoline-based compound demonstrated encouraging potential as a new class of chiral hypervalent iodine reagent.

Fujita et al. synthesized non $C_{2}$-symmetric chiral iodoarene reagents 9a derived from lactic acid derivatives and utilized them in stoichiometric fashion for the synthesis of chiral tetrahydrofuran derivatives [36]. A major breakthrough was achieved in this field by the discovery of a family of conformationally flexible $C_{2}$-symmetric chiral iodoarene reagents. Ishihara et al. thoughtfully designed a new class of $C_{2}$-symmetric chiral iodoarene precatalyst $\mathbf{8 a}$ using (-)-ethyl lactate as a chiral linker with the aromatics attached followed by its successful conversion to the amide derivative to generate precatalyst $\mathbf{8 a}$ [37,38]. Application of this precatalyst $\mathbf{8 a}$ was employed for the Kita oxidation [32] with a high level of enantioselectivity. Naphthol derivatives $\mathbf{3 1}$ were converted to spirocyclic lactones 


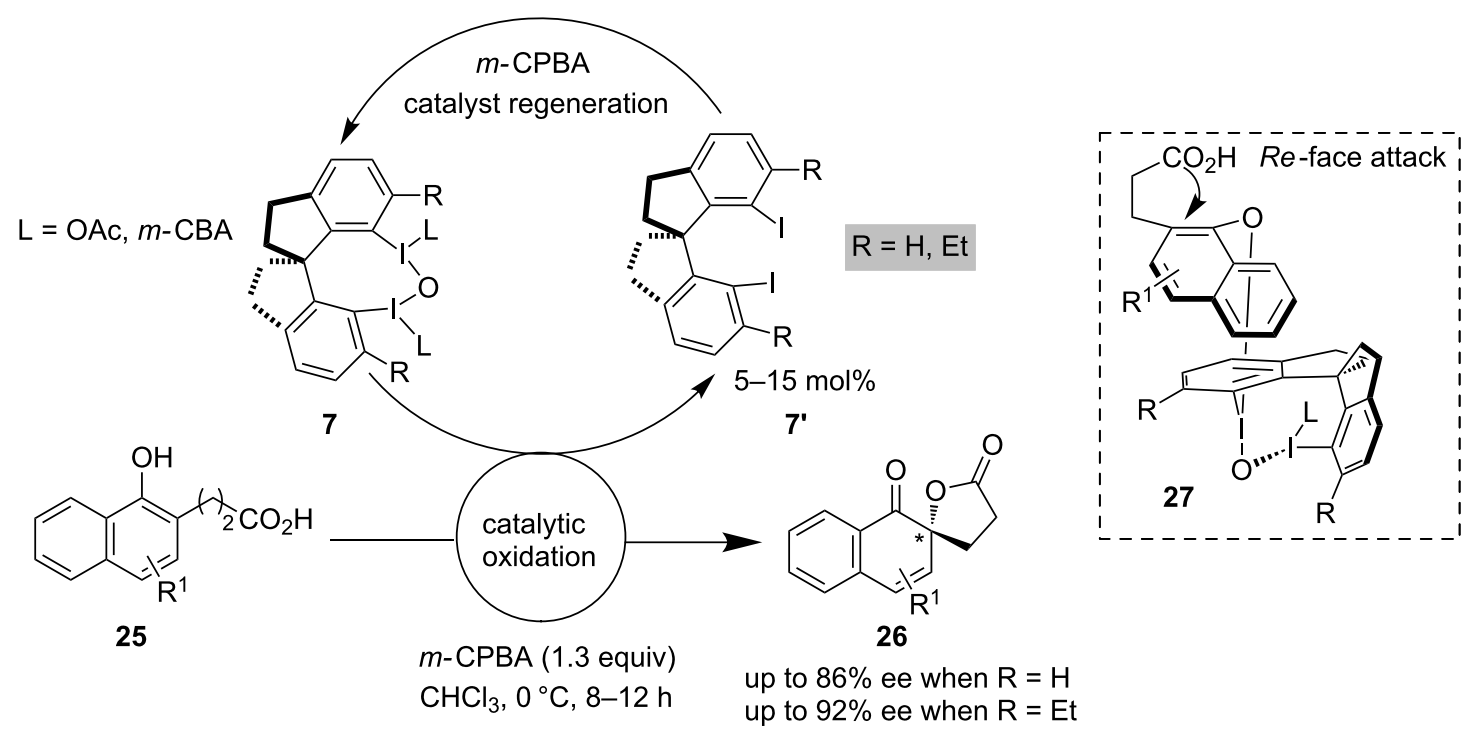

Scheme 3: Oxidative dearomatization of naphthol derivatives by Kita et al.

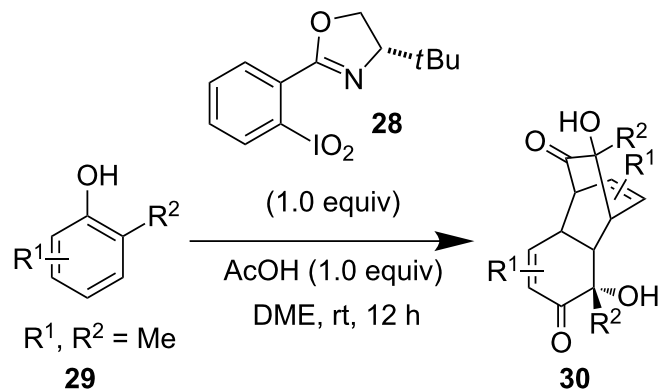

29

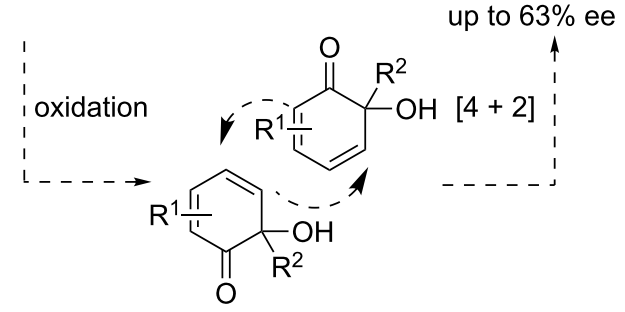

Scheme 4: [4 + 2] Diels-Alder dimerization reported by Birman et al.
32 in the presence of $m$-CPBA as co-oxidant for the in situ generation of the I(III) catalyst. Secondary $n-\pi^{*}$ and/or hydrogenbonding interactions of the catalyst ensured remarkable enantioselectivities (Scheme 5).

Later, this dearomatization strategy was further reinvestigated by the Ishihara group using a new chiral iodine precatalyst $\mathbf{1 0}$ derived from a chiral 2-aminoalcohol [39]. Its application in the oxidative dearomatization of phenol $\mathbf{3 3}$ and the subsequent reaction of the so-obtained dienes $\mathbf{3 4}$ with different dienophiles furnished Diels-Alder adducts $\mathbf{3 5}$ with excellent enantioselectivity. Intramolecular H-bonding and the presence of an achiral alcohol as additive helped them to achieve outstanding enantioselectivity (up to $99 \%$ ) even when using very low catalyst loadings (1-10 mol \%, Scheme 6)

Ciufolini et al. further carefully modified precatalyst $\mathbf{1 0}$ to generate a new chiral iodine precatalyst 11 [40]. They critically altered the chiral center next to the amide NH group to achieve

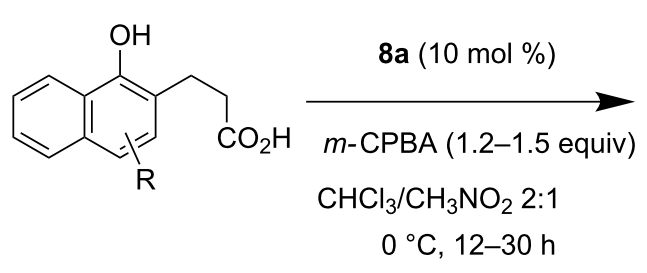

31<smiles></smiles>

up to $99 \%$ ee after recrystallization

32<smiles>CNC(=O)C(C)Oc1cccc(OC(C)C(=O)NC)c1I</smiles>

$8 a$ 
<smiles>[R]c1c([R])c([R])c(CCC(=O)O)c(O)c1[R]</smiles>

33

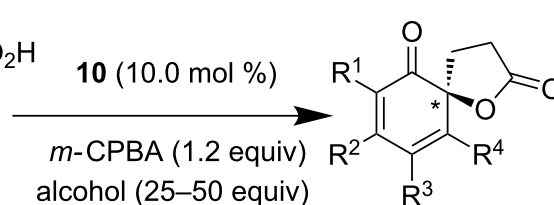

$\mathrm{CH}_{2} \mathrm{Cl}_{2},-10^{\circ} \mathrm{C}$
34

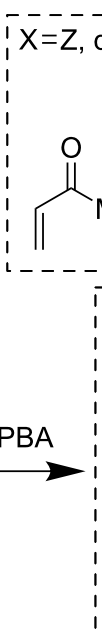

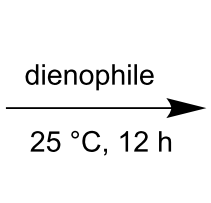

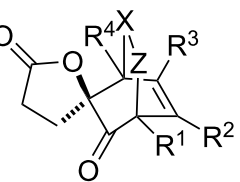

35

up to $99 \%$ ee

after recrystallization alcohol = methanol, hexafluoroisopropanol<smiles>[2H]N(CC(C)Oc1cccc(O[C@@H](C)CN(C)C(=O)c2c(C)cc(C)cc2C)c1I)C(=O)c1c(C)cc(C)cc1C</smiles>

$m$-CPBA

dienophile

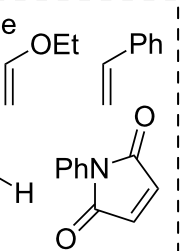

10

Scheme 6: Oxidative dearomatization of phenolic derivatives by Ishihara et al.

a high catalyst efficiency (Scheme 7). The crucial point is the better hydrogen-bonded conformation of $\mathbf{1 1}$ which imparted superior reactivity compared to Ishihara's system without the need of achiral alcohols as an additive. Profitable results were obtained regarding the oxidative cyclization of phenolic derivatives $\mathbf{3 6}$ to spirocyclic compounds $\mathbf{3 7}$.

Chiral hypervalent iodine reagents having binaphthyl backbones were used by Quideau et al. for the $\alpha$-hydroxylation of phenolic derivatives via oxygenative dearomatization. Quideau et al. showed that iodobiarene $\mathbf{3 8}$ was oxidized in situ by $m$-CPBA to generate the I(III) reagent which is responsible for the hydroxylative naphthol dearomatization affording the product in moderate enantioselectivity (Scheme 8 upper part). By this method naphthol $\mathbf{3 9}$ could be oxidized to chiral $o$-quinol $\mathbf{4 0}$ with $50 \%$ ee [41]. Varying the catalyst loading could alter the reaction outcome to afford either $o$-quinol $\mathbf{4 0}$ or epoxy $o$-quinol 41.

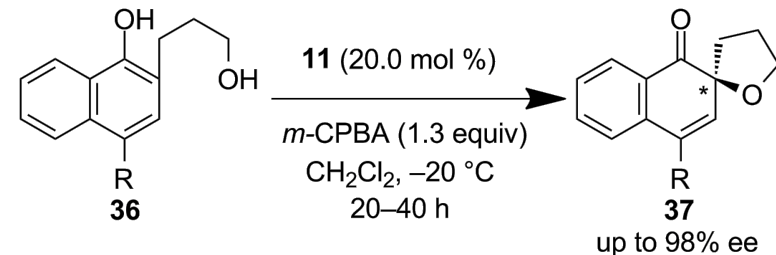

chiral center

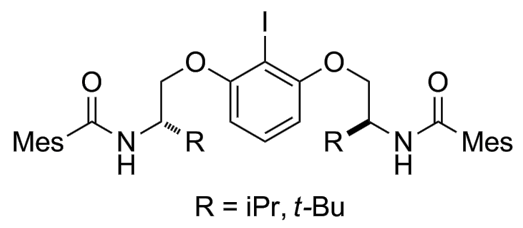

11 


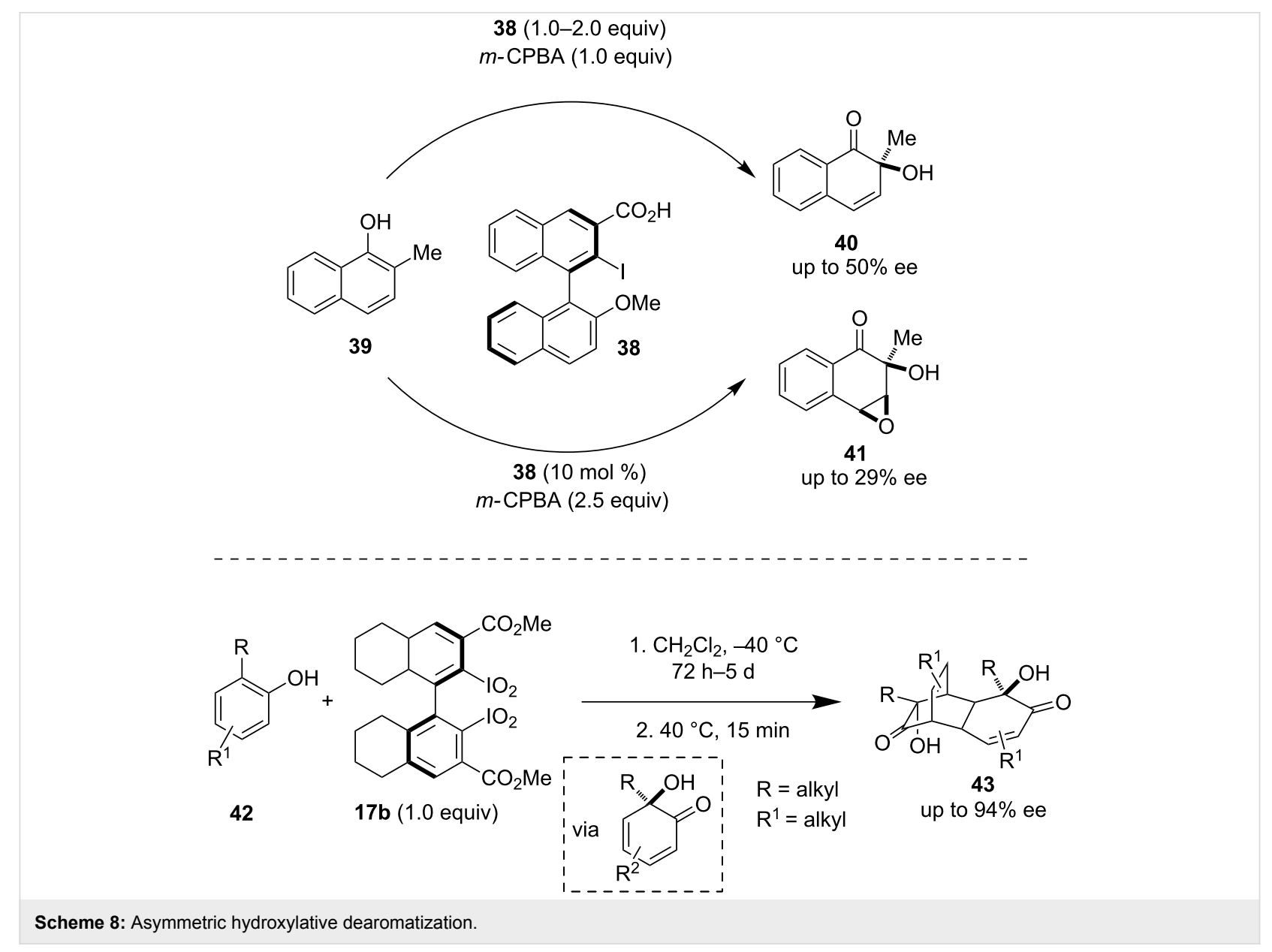

Recently, Pouységu and Quideau et al. modified their iodobiarenes to synthesize a new class of I(III) and I(V) reagents 17. These were applied for the hydroxylative dearomatization of phenolic derivatives $\mathbf{4 2}$ followed by the successive use of the hydroxylated products as dienes in [4+2] cycloaddition reactions [42]. This new reagent promoted oxygen transfer in phenol dearomatization, leading to the formation of cyclodimerization products $\mathbf{4 3}$ with high enantioselectivity (up to $94 \%$ ee, Scheme 8 lower part).

\section{Alkene functionalization}

Nearly simultaneously to Ishihara's work, Fujita et al. reported on the modification of their previously synthesized non $C_{2}$-symmetric reagent 9a to obtain a $C_{2}$-symmetric chiral iodoarene reagent $9 \mathbf{b}$ having an ester end group instead of an amide (as in case of Ishihara's work). The enantioselective oxylactonization was achieved efficiently using stoichiometric amounts of chiral reagent $\mathbf{9 b}$ (Scheme 9). This lactate-derived I(III) reagent $\mathbf{9 b}$ was used successively for the synthesis of $\delta$-lactones 45 in a highly stereoselective manner starting from 44 [43]. The formation of cyclic iodonium $\mathbf{4 6}$ is the vital part of this difunctionalization process.
Wirth et al. were the first to introduce asymmetric dioxytosylation of styrene (47) using a new class of chiral hypervalent iodine reagents $49-52$ to furnish 48 with moderate enantioselectivity (Scheme 10) [44-47]. Their constant efforts towards alkene dioxygenation helped them to discover new chiral hypervalent iodine reagents and also to reach up to $65 \%$ enantioselectivity using $\mathbf{5 2}$.

Fujita et al. further explored the difunctionalization strategy for the development of diacetoxylation of alkenes following a Prevost and Woodward reaction [48]. Recently, the same group used chiral iodine reagent $\mathbf{5 5}$ together with acid co-reagent for the intramolecular oxyarylation and aminoarylation of alkenes 53 to produce 54 (Scheme 11). The presence of a silyloxy group is essential to achieve high enantioselectivity in case of the oxyarylation [49]. The Lewis acid activates the hypervalent chiral iodine reagent and then adds to the alkene system. The nucleophilic addition of the internal oxy/amino group followed by the nucleophilic addition of the aryl group delivers the desired products 54. The key to success also lies on the enantiotopic face discrimination of the alkene by the lactate-based chiral iodine reagent. 
<smiles>[R]C=Cc1ccccc1C(=O)OC</smiles>

44

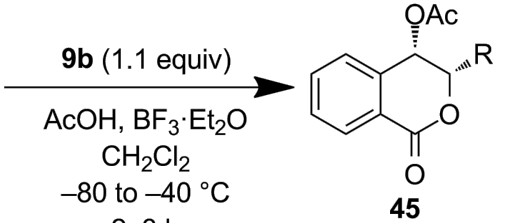

up to $97 \%$ ee

$\mathrm{R}=\mathrm{H}, \mathrm{CH}_{2} \mathrm{OMe}, \mathrm{CH}_{2} \mathrm{OH}, n-\mathrm{C}_{5} \mathrm{H}_{11}$

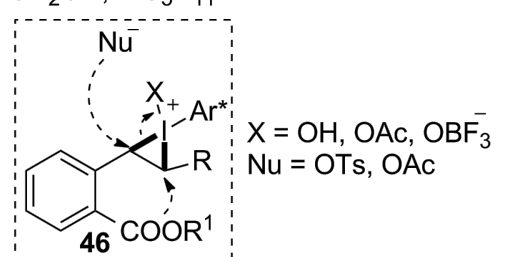<smiles>[R]c1cccc(OC(C)C(=O)OC)c1I(OC(C)=O)OC(C)=O</smiles><smiles>[R]OC(=O)C(C)OC</smiles>

$9 b$

Scheme 9: Enantioselective oxylactonization reported by Fujita et al.

$$
\begin{aligned}
& \text { chiral iodine reagents } \\
& 47 \underset{\substack{\mathrm{PhOH}\left(1.0 \text { equiv) } \\
\mathrm{CH}_{2} \mathrm{Cl}_{2}\right.}}{(1.0 \text { equiv })} \underset{\mathrm{Ph}_{48}^{\mathrm{OT}} \mathrm{OTs}}{\mathrm{PT}}
\end{aligned}
$$<smiles>CCC1O[Te]([O-])(O)c2ccccc21</smiles>

49

up to $21 \%$ ee

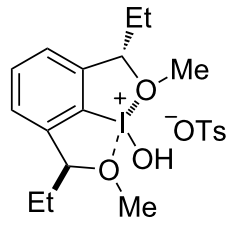

50<smiles></smiles>

up to $17 \%$ ee<smiles>COc1cccc2c1[I-]([O-])(O)OC2C</smiles>

51

up to $53 \%$ ee

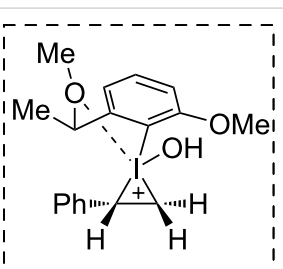<smiles>CCc1cccc2c1[I-]([O-])(O)OC2C</smiles>

52

up to $65 \%$ ee

Scheme 10: Dioxytosylation of styrene (47) by Wirth et al.

This difunctionalization strategy was further showcased by Muñiz et al. as intermolecular diamination protocol of alkenes 56 using 9b (Scheme 12) [50]. This represented the first example of an asymmetric diamination of simple nonfunctionalized alkenes to acquire diaminated products 57 . The existence of an I(III)-N bond under ligand exchange conditions and the formation and ring opening of aziridinium intermediate $\mathbf{5 8}$ elucidate the product formation in this transformation [51].

Wirth et al. successfully employed I(III) reagent $\mathbf{8 b}$ in combination with trimethylsilyltriflate (TMSOTf) for the stereoselective oxyamination of $\mathbf{5 9}$ to furnish isourea $\mathbf{6 0}$ with $>99 \%$ ee
(Scheme 13) [52]. Both the Lewis acid and solvent used play an important role in this transformation. This method was applied to the synthesis of other isourea derivatives 62-64 with moderate enantioselectivity. The reactions were triggered by the activation of olefins followed by the formation of $\mathrm{C}-\mathrm{N}$ bonds. The subsequent intramolecular substitution reaction of intermediate 61 having hypervalent iodine as a good leaving group yielded the required heterocycles.

After Wirth's report, Nevado et al. discovered a newly modified chiral iodine reagent $\mathbf{1 3}$ analogous to lactate-based chiral iodoarenes [53]. They have utilized this chiral difluoroiodo- 
<smiles>[R][X]CC/C=C\CCc1ccc([R])cc1</smiles>

53

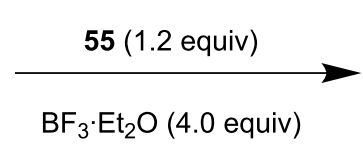

$\mathrm{CH}_{2} \mathrm{Cl}_{2},-80^{\circ} \mathrm{C}, 1 \mathrm{~h}$<smiles>[R]c1ccc2c(c1)[C@H]1CC[Y][C@H]1CC2</smiles>

54

up to $95 \%$ ee

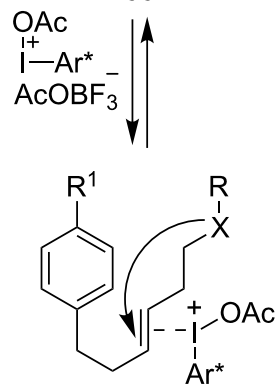<smiles>[R]c1ccc(CCC2CCCC2CC)cc1</smiles><smiles>CCCCOC(=O)C(C)Oc1ccccc1I(OC(C)=O)OC(C)=O</smiles>

55 $\mathrm{X}=\mathrm{O}, \mathrm{R}=\mathrm{H}$, TBS, TES, TIPS, TBDPS TBS $=$ tert - butyldimethylsilyl TES $=$ triethylsilyl TIPS = triisopropylsilyl TBDPS = tert -butyldiphenylsilyl $\mathrm{X}=\mathrm{NMs}, \mathrm{R}=\mathrm{H}$ $\mathrm{Ms}=$ methanesulfonyl $\mathrm{R}^{1}=\mathrm{H}, \mathrm{OMe}, \mathrm{Me}, \mathrm{Br}, \mathrm{F}, \mathrm{CF}_{3}$

Scheme 11: Oxyarylation and aminoarylation of alkenes

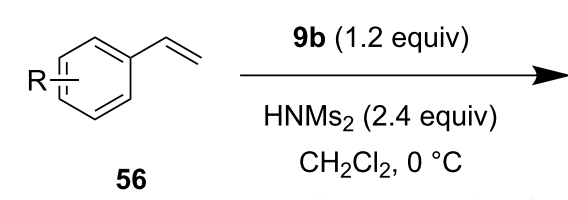

$\mathrm{X}=\mathrm{Ms}$ (methanesulfonyl)
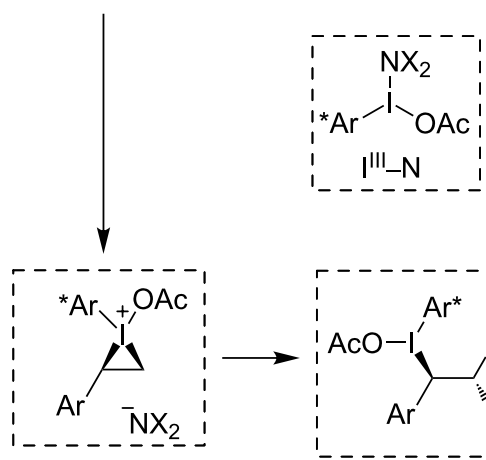

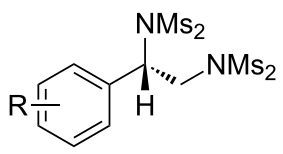

57

up to $99 \%$ ee

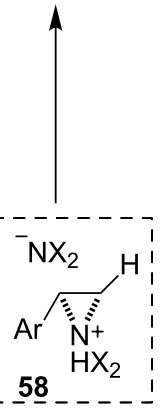<smiles>[R]c1cccc(OC(C)C(=O)OC)c1I(OC(C)=O)OC(C)=O</smiles><smiles></smiles>

$9 b$

Scheme 12: Asymmetric diamination of alkenes.

nium salt $\mathbf{1 3}$ for the asymmetric synthesis of aminofluorinated compounds 66 from 65 (Scheme 14). In addition to this, they extended this methodology for the regioselective intermolecular aminofluorination of styrenes with a racemic catalyst. The nucleophilic attack of the nitrogen atom onto the alkene (intermediate 67) to generate aziridinium ion $\mathbf{6 8}$ is the crucial step in this transformation.
Recently, Jacobsen et al. developed a highly stereoselective difunctionalization method for the synthesis of chiral fluorinecontaining molecules and the 1,2-difluorination, 1,1-difluorination and fluorolactonization protocols appeared almost simultaneously (Scheme 15). The lactate-based $C_{2}$-symmetric chiral iodine precatalysts $\mathbf{7 3}, \mathbf{7 6}$, and 79 were used to deliver chiral fluorinated scaffolds from alkene starting materials 69 in the 
<smiles>C=C(CCCNC(=O)NS)c1ccccc1</smiles>

59

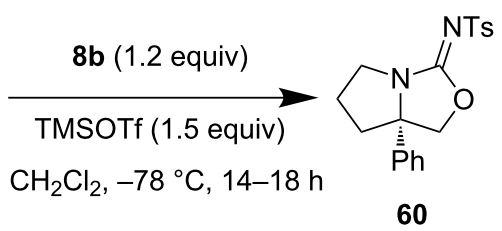

$>99 \%$ ee

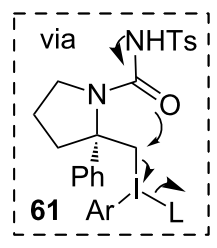<smiles>CCCCNC(=O)C(C)Oc1cccc(OC(C)C(=O)NC)c1I(OC(C)=O)OC(C)=O</smiles>

Mes $=$ mesityl

$8 b$
62 $79 \%$ ee<smiles>FC(F)(F)c1ccc(/N=C2\OCC3CC(c4ccccc4)(c4ccccc4)CN23)cc1</smiles>

63 $39 \%$ ee<smiles></smiles>

64 $61 \%$ ee

Scheme 13: Stereoselective oxyamination of alkenes reported by Wirth et al.

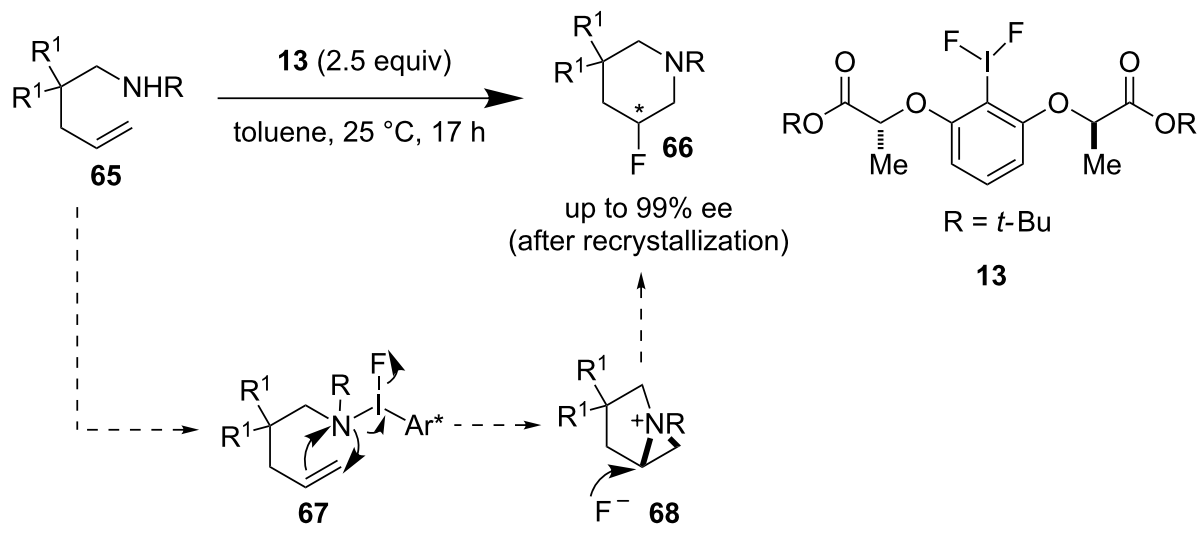

$\mathrm{R}=\mathrm{Ts}, \mathrm{Ns}, \mathrm{Cbz}, \mathrm{MeSO}_{2}, \mathrm{ArSO}_{2}$

$\mathrm{Ns}=$ 2-nitrobenzenesulfonyl, $\mathrm{Cbz}=$ carbobenzyloxy

$\mathrm{R}^{1}=\mathrm{H}, \mathrm{Me}, \mathrm{Ar}$

Scheme 14: Enantioselective and regioselective aminofluorination by Nevado et al.

presence of pyrHF as a nucleophilic fluoride source. The reactions were guided by the formation of intermediate $\mathbf{7 0}$. Anchimeric assistance via the phenonium ion intermediate $\mathbf{7 1}$ and subsequent ring-opening rearrangement delivered the 1,1difluorinated products $\mathbf{7 2}$ in the presence of catalyst 73 [54]. On the other hand the anchimeric assistance via participation of the amide carbonyl group (intermediate 74) dictated the formation of 1,2-difluorinated products $\mathbf{7 5}$ and catalyst $\mathbf{7 6}$ was identified as the optimal catalyst for this transformation. The 1,2-difluorinated products $\mathbf{7 5}$ can also be obtained with high diastereoselectivity by an anchimeric assistance of an $o-\mathrm{NO}_{2}$ group present in the aryl ring [55]. The authors cleverly replaced the $o-\mathrm{NO}_{2}$-substituent with a $\mathrm{CO}_{2} \mathrm{R}$ group $(\mathrm{R}=\mathrm{H}$ or $\mathrm{Me})$. With this modification they were able to obtain fluorolactonization products with high enantioselectivity using $\mathbf{7 9}$ as a catalyst, via the intramolecular displacement of the aryl iodide by the $\mathrm{CO}_{2} \mathrm{R}$ group in $\mathbf{7 7}$ leading to chiral lactones of type $\mathbf{7 8}$ [56].

\section{Rearrangement strategy}

Wirth et al. used I(III) reagent $\mathbf{8 b}$ for the development of a stereoselective oxidative rearrangement method to synthesize $\alpha$-arylated carbonyls $\mathbf{8 1}$ from $\alpha, \beta$-unsaturated carbonyls $\mathbf{8 0}$ (Scheme 16, upper part) $[57,58]$. The reaction proceeds via the formation of the phenyliodinate intermediate $\mathbf{8 2}$ followed by a stereoselective 1,2-aryl migration. Elegantly, they utilized the 1,2-aryl migration approach to develop an enantioselective oxidative rearrangement of 1,1-disubstituted olefins $\mathbf{8 3}$ leading to the formation of valuable $\alpha$-arylated ketones $\mathbf{8 4}$. In this reaction 
<smiles>O=C(Cc1ccccc1)C(Br)Oc1cccc(OC(Cc2ccccc2)C(=O)Cc2ccccc2)c1I</smiles>

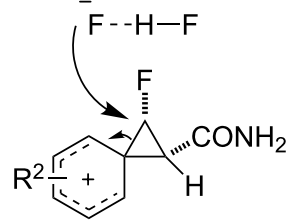

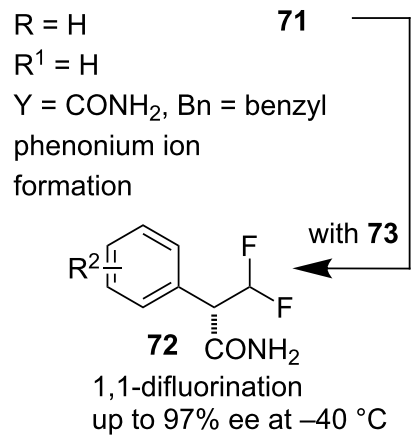

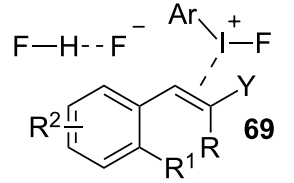
catalyst pyr.HF 1,2-fluoroiodination $m$-CPBA $y$<smiles>COC(=O)C(Cc1ccccc1)Oc1cccc(OC(Cc2ccccc2)C(C)=O)c1I</smiles>

76

F-- H-F

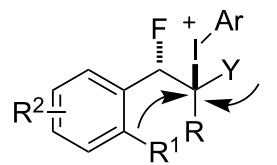
70

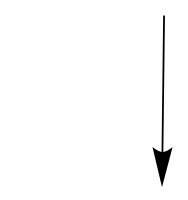

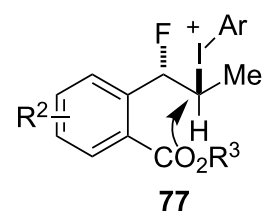

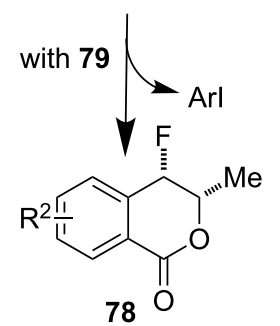

$\mathrm{R}=\mathrm{H}$ $\mathrm{R}^{1}=\mathrm{CO}_{2} \mathrm{R}^{3}$ $\mathrm{R}^{3}=\mathrm{H}, \mathrm{Me}$ $\mathrm{Y}=\mathrm{Me}$ $\mathrm{R}^{2}=\mathrm{H}, \mathrm{Me}, 5-\mathrm{Cl}, 5-\mathrm{Br}, \mathrm{F}, 5-\mathrm{CF}_{3}, 4-\mathrm{CF}_{3}$, $5-\mathrm{CO}_{2} \mathrm{Me}, 4-\mathrm{CO}_{2} \mathrm{Me}, 5-\mathrm{OCF}_{3}$

fluorolactonization

up to $96 \%$ ee at $-50{ }^{\circ} \mathrm{C}$

Scheme 15: Fluorinated difunctionalization reported by Jacobsen et al.

I(III) reagent $9 \mathbf{b}$ gave the best reaction outcome. Key to the success of the reaction is the formation of the cyclic iodonium ion intermediate $\mathbf{8 5}$ (Scheme 16, below part) [59,60].

\section{Asymmetric $\alpha$-functionalization strategy}

Methods for carbonyl $\alpha$-functionalizations are still considered as highly demandable in synthetic organic chemistry. In this regard transition metals have been successfully applied and even allow accomplishing such transformations asymmetrically. On the other hand, diaryliodonium salts are known to transfer aryl groups ultimately leading to $\alpha$-arylated products. This part of the review focuses on the development of $\alpha$-functionalization strategies based on chiral diaryliodonium reagents having either an axially chiral backbone or that can be considered analogous to the $C_{2}$-symmetric iodoarene moiety. For this purpose various chiral iodine reagents were synthesized having an axially chiral biaryl backbone. In this part, we mainly focused on the transformations using chiral iodine reagents instead of achiral iodine reagents in a combination with other chiral sources [61].

More than one century after Pribam discovered diphenyliodonium tartrate [23], Ochiai et al. realized the introduction of chirality through incorporation of binaphthyl backbones [62] and they synthesized new classes of chiral hypervalent iodine reagents 15. Later, to ensure asymmetric transformations, the same group developed the synthesis of more effective chiral iodonium salts $\mathbf{1 6}$ which were used for the $\alpha$-arylation of $\beta$-ketoester 86 to deliver $\alpha$-arylated $\beta$-ketoesters 87 with moderate enantioselectivity (Scheme 17) [63]. This was the first example of an asymmetric $\alpha$-arylation of $\beta$-ketoesters using hypervalent iodine reagents. A more reactive organostannane derived $\mathrm{Sn}-\mathrm{I}(\mathrm{III})$ exchange in the presence of $\mathrm{BF}_{3} \cdot \mathrm{Et}_{2} \mathrm{O}$ was the crucial step in the synthesis of the chiral iodonium salts from $\mathbf{8 8}$. 


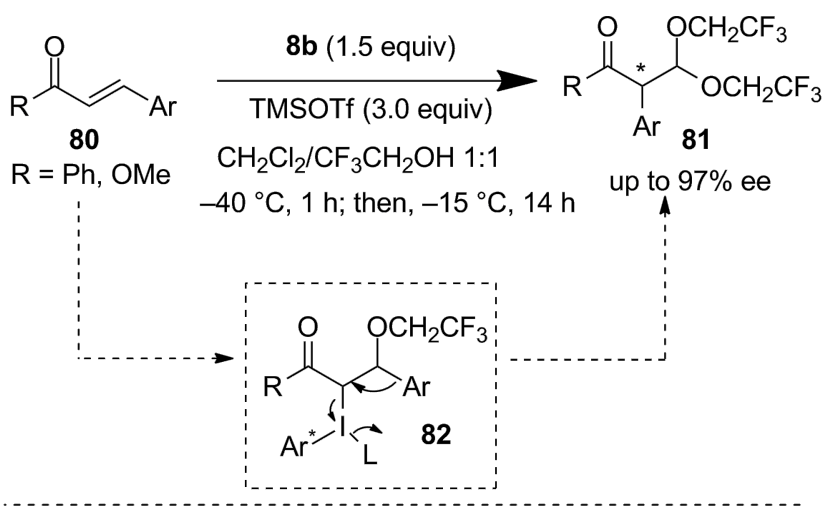

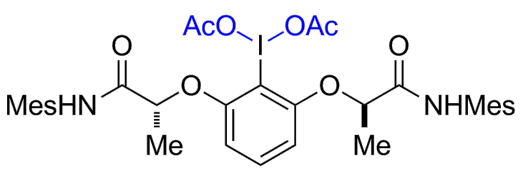

Mes $=$ mesityl

$8 b$

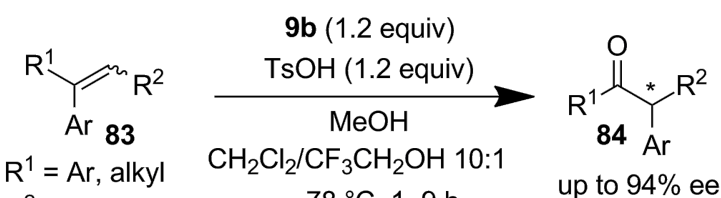

$\begin{array}{ll}\mathrm{R}^{1}=\mathrm{Ar} \text {, alkyl } & -78{ }^{\circ} \mathrm{C}, 1-9 \mathrm{~h} \quad \text { up to } 94 \% \text { ee }\end{array}$

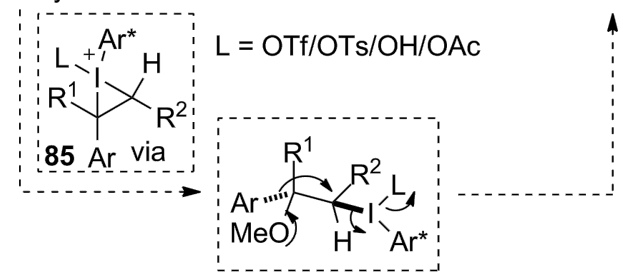<smiles>[R]c1cccc(OC(C)C(=O)OC)c1I(OC(C)=O)OC(C)=O</smiles><smiles>[R]=COC(=O)C(C)OC</smiles>

$9 b$

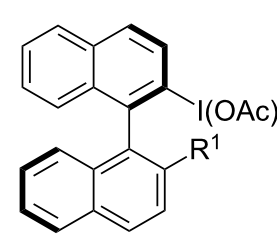

$\mathrm{R}^{1}=\mathrm{H}, \mathrm{Bn}$

88

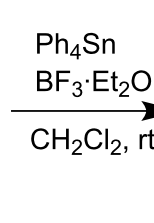

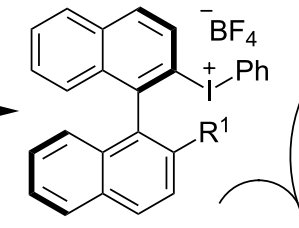

16<smiles>CC(=O)C1Cc2ccccc2C1=O</smiles>

86

$t$-BuOK up to $53 \%$ ee

$20 \mathrm{~h}$

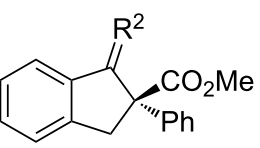

$\mathrm{R}^{2}=\mathrm{O}, \mathrm{S}\left(\mathrm{CH}_{2}\right)_{2} \mathrm{~S}$

87

Scheme 17: $\alpha$-Arylation of $\beta$-ketoesters.

In view of developing asymmetric $\alpha$-arylations of carbonyls, Olofsson et al. has independently synthesized a new class of diaryliodonium salts $\mathbf{1 4}$ with different stereoelectronic properties by using aliphatic alcohols as a sole source of chirality [64]. Olofsson and Wirth et al. also jointly reported the synthesis of new structurally distinct chiral reagents $\mathbf{2 0}$ considering their interest towards asymmetric metal-free arylation [65].

In 1997, Wirth et al. for the first time reported an asymmetric $\alpha$-oxytosylation of propiophenone using hypervalent iodine reagents 49/50 [45]. Later they improved the enantioselectivity by a structurally modified catalyst $\mathbf{5 1}$ to obtain up to $28 \%$ ee [46]. After a further few years, in 2001, they came up with a modified catalyst $\mathbf{5 2}$ which allowed them to reach up to $40 \%$ ee [47]. A catalytic variant of this methodology was developed by the same group using $m$-CPBA as co-oxidant together with catalyst 89 to get up to $39 \%$ ee [66] (Scheme 18).

In 2013, Berthiol and Einhorn et al. demonstrated an intermolecular asymmetric $\alpha$-oxytosylation of ketones by using a new 


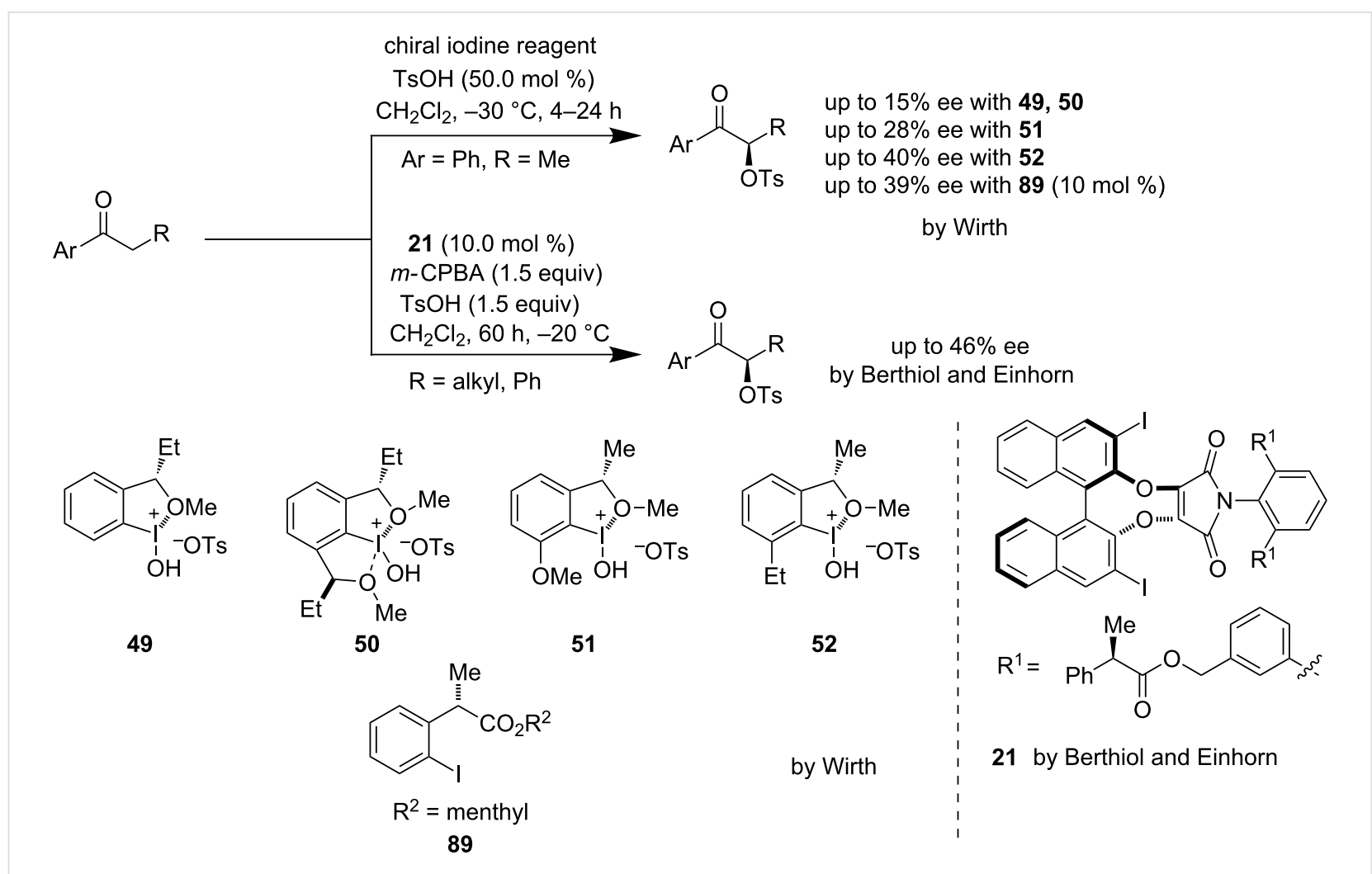

Scheme 18: Asymmetric a-oxytosylation of carbonyls.

family of chiral hypervalent iodine catalyst $\mathbf{2 1}$ with up to $46 \%$ ee [67]. The investigation of the reaction mechanisms revealed that the steric crowding around the iodine center improves the enantioselectivity (Scheme 18).

Asymmetric oxygenation and nitrogenation reactions of carbonyls were established by Wirth et al. Nucleophile transfer from silyl enol ethers $\mathbf{9 0}$ delivered $\alpha$-functionalized carbonyls 91 with good enantioselectivity [68]. "Umpolung" reactivity and silyl-tethered enol ethers allowed the delicate synthesis of $\alpha$-functionalized carbonyls (Scheme 19). $C_{2}$-symmetric I(III) reagent $\mathbf{8 b}$ was used to obtain high enantioselectivity.
Ishihara et al. appealingly reported an oxidative cycloetherification of ketophenols $\mathbf{9 2}$ in the presence of an in situ generated chiral quaternary ammonium (hypo)iodite salt 94, with hydrogen peroxide as an oxidant to deliver chiral dihydrobenzofuran derivatives 93 as $\alpha$-functionalized products of ketophenols $\mathbf{9 2}$ (Scheme 20) [69]. The substituents at the 3,3'-position of the binaphthyl moiety of the salt $\mathbf{9 4}$ played a crucial role to achieve high enantioselectivities up to $96 \%$.

Very recently, Gong et al. developed an asymmetric oxidative intramolecular cross-coupling of $\mathrm{C}-\mathrm{H}$ bonds in 95 using catalytic chiral iodine $\mathbf{1 2}$ for the synthesis of a diverse array of

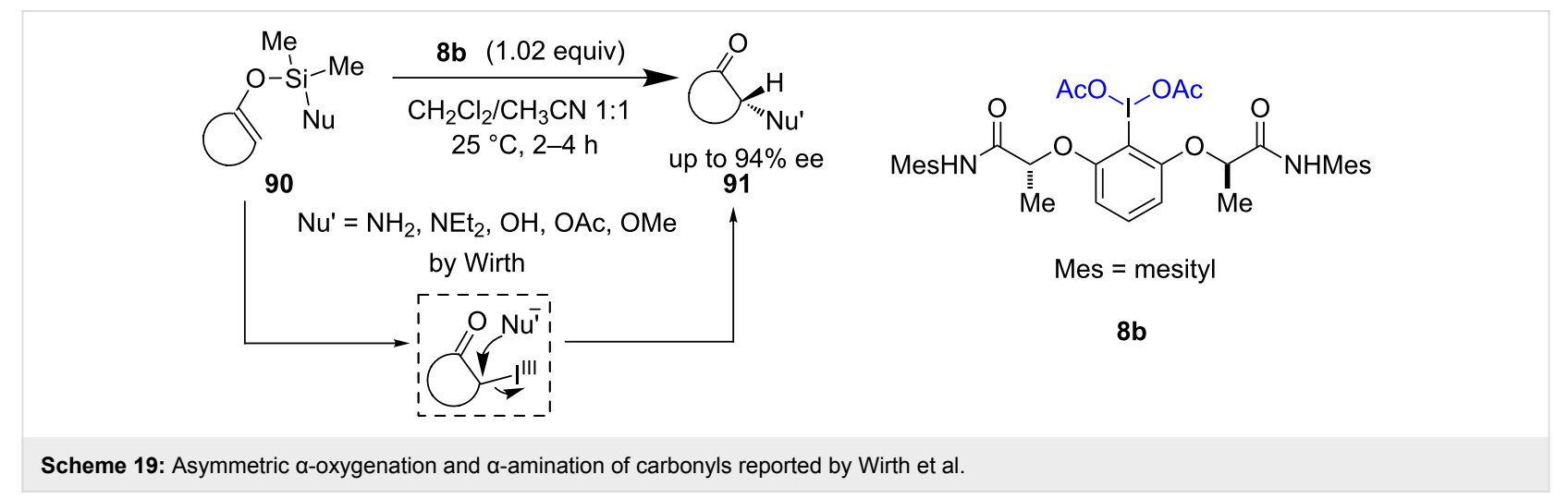




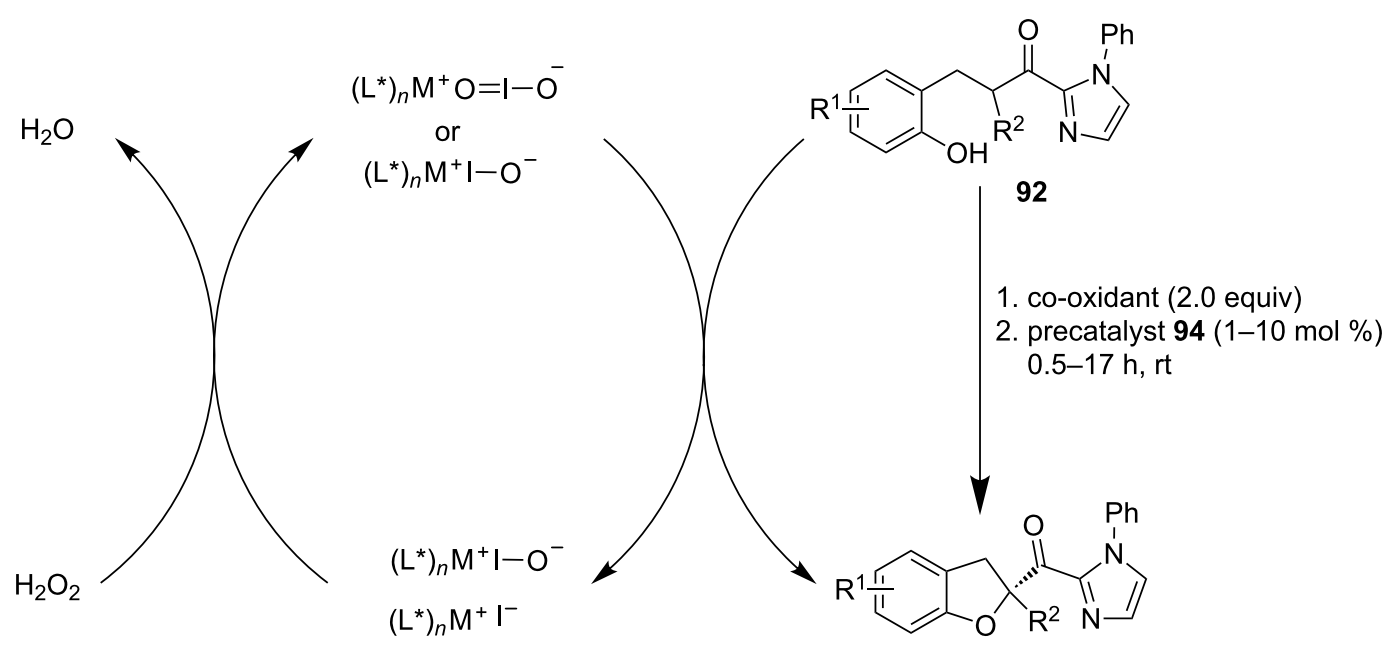

93

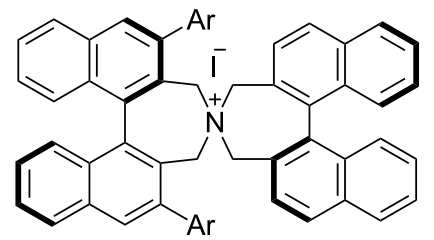

up to $96 \%$ ee

Method $1:$ co-oxidant $=30 \% \mathrm{H}_{2} \mathrm{O}_{2}, \mathrm{Et}_{2} \mathrm{O} / \mathrm{H}_{2} \mathrm{O} 5: 1$

Method 2 : co-oxidant $=\mathrm{TBHP}, \mathrm{Et}_{2} \mathrm{O}$

$$
\begin{aligned}
\mathrm{R}^{1}= & \mathrm{H}, 3,5-\mathrm{Me}_{2}, 3,5-(\mathrm{OMe})_{2}, 4-\mathrm{Cl}, \\
& 4-\mathrm{F}, 4-\mathrm{OCF}_{3}, 4-\mathrm{OMe}, 4-\mathrm{OBn}, \\
& 3,5,6-\mathrm{Me}_{3}-4-\mathrm{OSiMe}_{2} t-\mathrm{Bu} \\
\mathrm{R}^{2}= & \mathrm{H}, \mathrm{Me}
\end{aligned}
$$

$94 \mathrm{Ar}=3,5-\left[3,5-\left(\mathrm{CF}_{3}\right)_{2} \mathrm{C}_{6} \mathrm{H}_{3}\right] \mathrm{C}_{6} \mathrm{H}_{3} \quad$ TBHP = tert-butylhydroperoxide

Scheme 20: Asymmetric a-functionalization of ketophenols using chiral quaternary ammonium (hypo)iodite salt reported by Ishihara et al.

spirooxindoles 96. Ishihara's catalyst was modified by using an (S)-proline derivative to achieve a high level of enantioselectivity in the presence of peracetic acid (Scheme 21) [70]. They postulated the formation of possible intermediate 97 which favored the nucleophilic attack of the aryl ring from the less sterically hindered side. Later, Du et al. used this same precata-

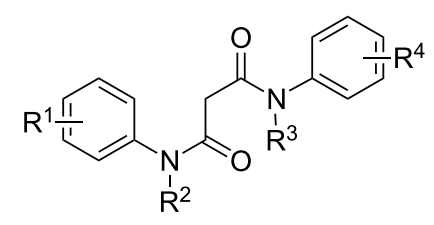

95

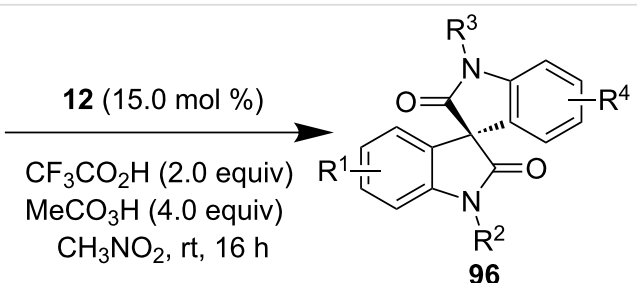

up to $90 \%$ ee

$\mathrm{R}^{1}=\mathrm{R}^{4}=\mathrm{H}$, alkyl

$\mathrm{R}^{2}=\mathrm{R}^{3}=\mathrm{Me}, \mathrm{Bn}$

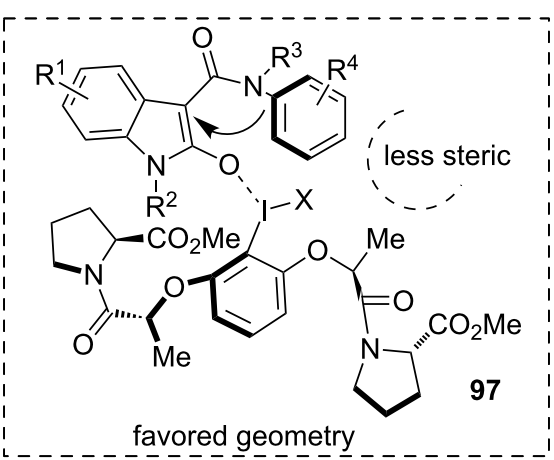<smiles>COC(=O)C1CCCN1C(=O)C(C)Oc1cccc(OC(C)C(=O)N2CCCC2C(C)=O)c1I</smiles>

12 
lyst 12 to obtain spirofurooxindole derivatives with high enantioselectivity through cascade cross-coupling sequences [71].

Latterly, Masson et al. reported a new chiral iodoarene prereagent 22 which they have used for the direct oxygenation of carbonyls 98. They were able to get $\alpha$-sulfonyls and $\alpha$-phosphoryl oxyketones 99 with moderate ees (Scheme 22) [72]. A new type of non $C_{2}$-symmetric chiral hypervalent reagent was utilized for the asymmetric $\alpha$-oxygenation of carbonyls. Nucleophilic attack of the oxygen nucleophile to the intermediate $\mathbf{1 0 0}$ or alternatively a reaction pathway through $O$-enolate intermediate $\mathbf{1 0 1}$ can explain the desired product formation.

In 2014, Kita and Shibata reported a catalytic, enantioselective, nucleophilic fluorinating technique of $\beta$-keto esters 102 using $\mathbf{1 0 6} / \mathrm{HF} / m-\mathrm{CPBA}$ as a catalytic system to access fluorinated $\beta$-keto esters 103 with moderate enantioselectivity [73]. $\beta$-Keto esters having sterically hindered adamantyl or menthyl groups lead to good selectivity. However, no further enhancement of ee could be achieved even by using a $50 \mathrm{~mol} \%$ catalyst loading. A nucleophilic attack of the fluoride ion to the intermediate 104 or a possible ligand coupling pathway via $\mathbf{1 0 5}$ could justify the product formation (Scheme 23).

Waser et al. developed an asymmetric alkynylation of $\beta$-ketoesters and amides $\mathbf{1 0 7}$ catalyzed by a phase-transfer catalyst [74]. Their previous findings on the same reaction using a Cinchona-based phase-transfer catalyst [75] was further improved by using Maruoka's binaphthyl-derived ammonium salt 110. The formation of intermediate $\mathbf{1 1 2}$ (chiral catalyst still attached to the substrate) from the enolate intermediate $\mathbf{1 1 1}$ followed by the generation of a $\mathrm{C}-\mathrm{C}$ bond via conjugate addition

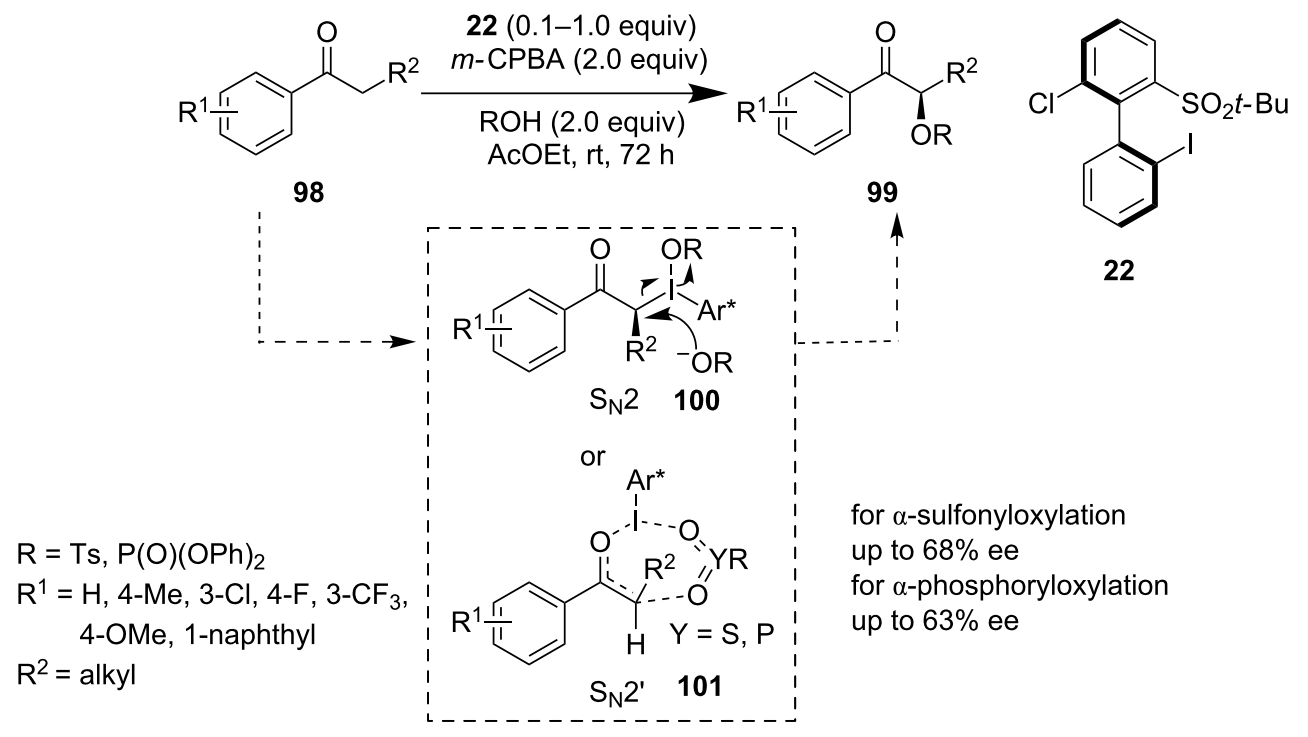

Scheme 22: a-Sulfonyl and a-phosphoryl oxylation of ketones reported by Masson et al.

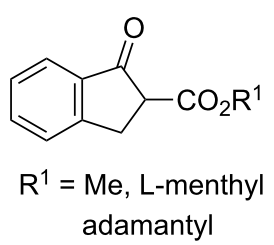

102

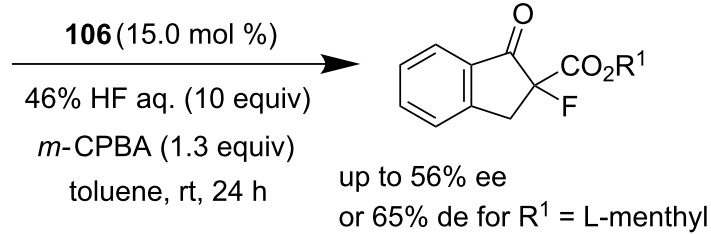

103<smiles>Ic1ccc2ccccc2c1-c1c(I)ccc2ccccc12</smiles>

106 
delivered intermediate carbene 113. A 1,2-hydrogen shift led to the formation of products $\mathbf{1 0 8}$ with enantioselectivities up to $79 \%$ (Scheme 24). Later, Maruoka et al. improved the enantioselectivity up to $95 \%$ ee for the alkynylation of $\beta$-ketoesters [76].

Pouységu and Quideau et al. prepared new axially chiral biaryl I(III) reagents 18 assembled with alkynyl ligands. They were able to achieve alkynylation of $\beta$-ketoesters $\mathbf{1 1 4}$ as well as dearomative alkynylation of phenolic derivatives $\mathbf{1 1 8}$ to obtain derivatives 115 and 119, respectively, with decent enantioselectivity (Scheme 25) [77]. The formation of an alkylidene carbene 117 and its rapid rearrangement via 1,2-silyl shift (in case of $\mathrm{R}=$ silyl group) into the alkylated $\beta$-ketoesters 115 can fairly explain the reaction outcome. On the other hand, the ligand exchange/coupling sequence through the iodosyl intermediate $\mathbf{1 1 6}$ can be an alternative pathway for the formation of 115. Likewise, a $\mathrm{C}-\mathrm{C}$ ipso-allyl ligand coupling via intermediate $\mathbf{1 2 0}$ from $O$-naphtholate 118 explains the formation of product 119.

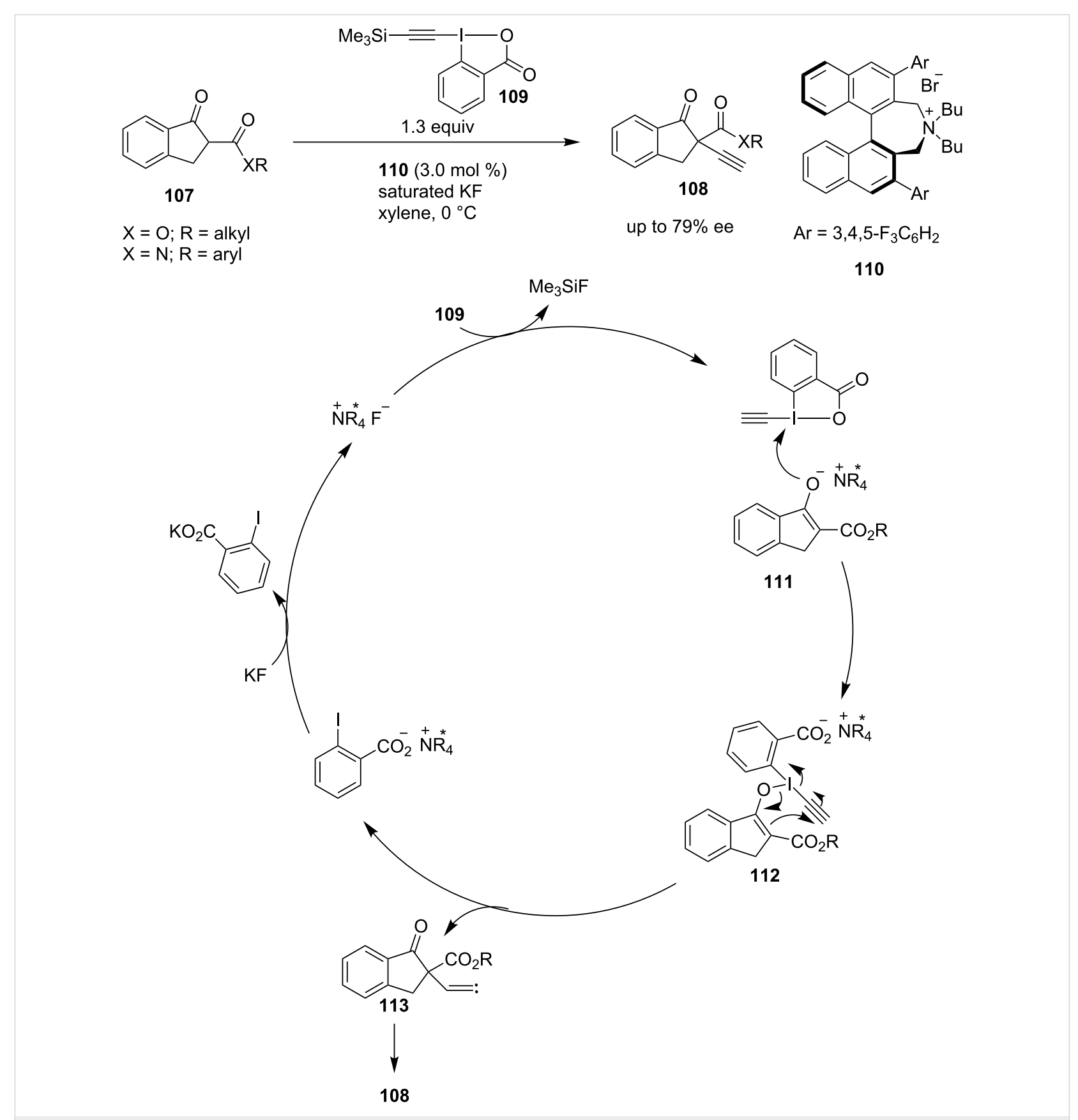

Scheme 24: Alkynylation of $\beta$-ketoesters and amides catalyzed by phase-transfer catalyst. 


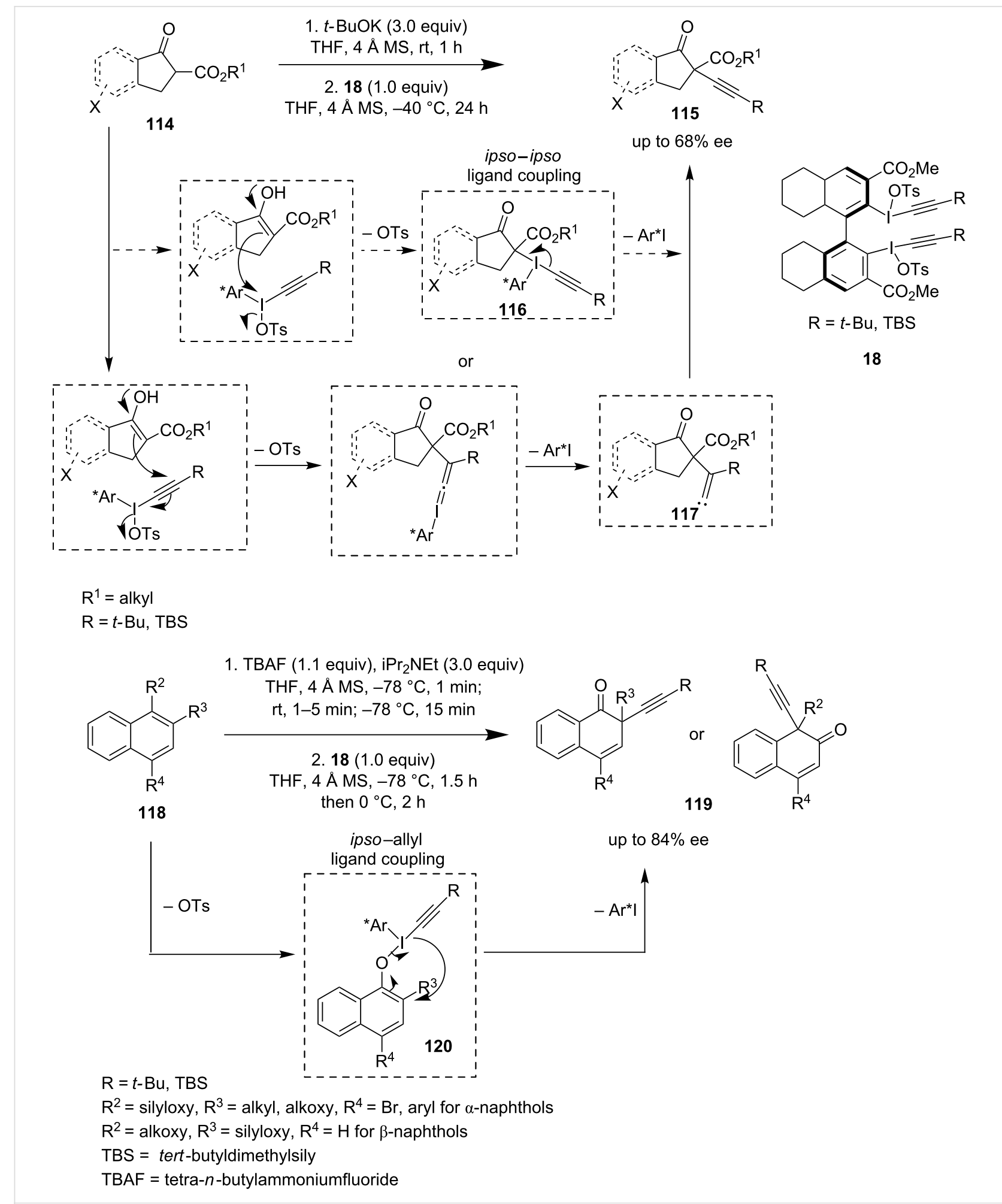

Scheme 25: Alkynylation of $\beta$-ketoesters and dearomative alkynylation of phenols.

\section{Conclusion}

To conclude, throughout this review we have seen substantial growth in the field of chiral hypervalent iodine reagents. This review points a number of striking chiral hypervalent iodine reagents used in stoichiometric or in catalytic fashion for quite a number of useful organic transformations. Most importantly the oxidative chemistry can be done using catalytic amounts of chiral hypervalent iodine reagents in the presence of an external 
oxidant. For convenient reading, we have only highlighted the optimized chiral catalysts or reagents used in the mentioned transformations. We hope that these new classes of reagents can achieve synthetically more challenging and application-oriented conversions that can be applied for the total synthesis of natural products as well as in industry related to pharmaceutical and medicinal chemistry.

These environmentally friendly, cheap and readily available reagents will surely attract the attention of scientists towards a sustainable replacement of transition metals. The application of chiral hypervalent iodine reagents is expected to pave the way for new reactions and reagent design in the field of asymmetric synthesis and catalysis.

\section{Acknowledgements}

The authors highly acknowledge the financial assistance received from the Indian Institute of Technology, Ropar. S. G. and. S. P. thank UGC, New Delhi and IIT Ropar, respectively, for their research fellowships. We thank Prof. Rano Ringo for proofreading the manuscript and valuable suggestions. We kindly acknowledge http://www.pexels.com/ from where we adapted our graphical abstract.

\section{ORCID ${ }^{\circledR}$ iDs}

Soumen Ghosh - https://orcid.org/0000-0002-0551-177X Suman Pradhan - https://orcid.org/0000-0002-5942-3206 Indranil Chatterjee - https://orcid.org/0000-0001-8957-5182

\section{References}

1. Willgerodt, C. J. Prakt. Chem. 1886, 33, 154-160. doi:10.1002/prac.18860330117

2. Zhdankin, V. V.; Stang, P. J. Chem. Rev. 2002, 102, 2523-2584. doi:10.1021/cr010003+

3. Zhdankin, V. V.; Stang, P. J. Chem. Rev. 2008, 108, 5299-5358. doi:10.1021/cr800332c

4. Yoshimura, A.; Zhdankin, V. V. Chem. Rev. 2016, 116, 3328-3435. doi:10.1021/acs.chemrev.5b00547

5. Zhdankin, V. V. ARKIVOC 2009, No. i, 1-62. doi:10.3998/ark.5550190.0010.101

6. Zhdankin, V. V. J. Org. Chem. 2011, 76, 1185-1197. doi:10.1021/jo1024738

7. Yusubov, M. S.; Zhdankin, V. V. Curr. Org. Synth. 2012, 9, 247-272. doi:10.2174/157017912799829021

8. Merritt, E. A.; Olofsson, B. Angew. Chem., Int. Ed. 2009, 48, 9052-9070. doi:10.1002/anie.200904689

9. Küpper, F. C.; Feiters, M. C.; Olofsson, B.; Kaiho, T.; Yanagida, S.; Zimmermann, M. B.; Carpenter, L. J.; Luther, G. W., III; Lu, Z.; Jonsson, M.; Kloo, L. Angew. Chem., Int. Ed. 2011, 50, 11598-11620. doi:10.1002/anie.201100028

10. Wirth, T. Synthesis 1999, 1271-1287. doi:10.1055/s-1999-3540

11. Wirth, T. Angew. Chem., Int. Ed. 2005, 44, 3656-3665. doi:10.1002/anie.200500115
12. Kitamura, T.; Fujiwara, Y. Org. Prep. Proced. Int. 1997, 29, 409-458. doi:10.1080/00304949709355217

13. Varvoglis, A. Tetrahedron 1997, 53, 1179-1255. doi:10.1016/S0040-4020(96)00970-2

14. Moriarty, R. M. J. Org. Chem. 2005, 70, 2893-2903. doi:10.1021/jo050117b

15. Kiprof, P. ARKIVOC 2005, No. iv, 19-25. doi:10.3998/ark.5550190.0006.403

16. Ochiai, M.; Sueda, T.; Miyamoto, K.; Kiprof, P.; Zhdankin, V. V. Angew. Chem., Int. Ed. 2006, 45, 8203-8206. doi:10.1002/anie.200603055

17. Sajith, P. K.; Suresh, C. H. Inorg. Chem. 2012, 51, 967-977. doi:10.1021/ic202047g

18. Gillespie, R. J.; Silvi, B. Coord. Chem. Rev. 2002, 233-234, 53-62. doi:10.1016/S0010-8545(02)00102-9

19. Akiba, K. y., Ed. Chemistry of Hypervalent Compounds; Wiley-VCH: New York, 1999.

20. Zhdankin, V. V. Hypervalent lodine Chemistry; John Wiley \& Sons Ltd.: New York, 2014.

21. Parra, A.; Reboredo, S. Chem. - Eur. J. 2013, 19, 17244-17260. doi:10.1002/chem. 201302220

22. Berthiol, F. Synthesis 2015, 47, 587-603. doi:10.1055/s-0034-1379892

23. Pribram, R. Justus Liebigs Ann. Chem. 1907, 351, 481-485. doi:10.1002/jlac.19073510139

24. Imamoto, T.; Koto, H. Chem. Lett. 1986, 967-968. doi:10.1246/cl.1986.967

25. Tohma, H.; Takizawa, S.; Watanabe, H.; Fukuoka, Y.; Maegawa, T.; Kita, Y. J. Org. Chem. 1999, 64, 3519-3523. doi:10.1021/jo982295t

26. Hatzigrigoriou, E.; Varvoglis, A.; Bakola-Christianopoulou, M. J. Org. Chem. 1990, 55, 315-318. doi:10.1021/jo00288a053

27. Xia, M.; Chen, Z.-C. Synth. Commun. 1997, 27, 1321-1326. doi:10.1080/00397919708006060

28. Zhdankin, V. V.; Smart, J. T.; Zhao, P.; Kiprof, P. Tetrahedron Lett. 2000, 41, 5299-5302. doi:10.1016/S0040-4039(00)00836-4

29. Ladziata, U.; Carlson, J.; Zhdankin, V. V. Tetrahedron Lett. 2006, 47, 6301-6304. doi:10.1016/j.tetlet.2006.06.103

30. Ray, D. G., III; Koser, G. F. J. Am. Chem. Soc. 1990, 112, 5672-5673. doi:10.1021/ja00170a059

31. Altermann, S. M.; Schäfer, S.; Wirth, T. Tetrahedron 2010, 66, 5902-5907. doi:10.1016/j.tet.2010.05.079

32. Dohi, T.; Maruyama, A.; Takenaga, N.; Senami, K.; Minamitsuji, Y.; Fujioka, H.; Caemmerer, S. B.; Kita, Y. Angew. Chem., Int. Ed. 2008, 47, 3787-3790. doi:10.1002/anie.200800464

33. Dohi, T.; Takenaga, N.; Nakae, T.; Toyoda, Y.; Yamasaki, M.; Shiro, M.; Fujioka, H.; Maruyama, A.; Kita, Y. J. Am. Chem. Soc. 2013, 135, 4558-4566. doi:10.1021/ja401074u

34. Dohi, T.; Sasa, H.; Miyazaki, K.; Fujitake, M.; Takenaga, N.; Kita, Y. J. Org. Chem. 2017, 82, 11954-11960. doi:10.1021/acs.joc.7b02037

35. Boppisetti, J. K.; Birman, V. B. Org. Lett. 2009, 11, 1221-1223. doi:10.1021/ol8029092

36. Fujita, M.; Okuno, S.; Lee, H. J.; Sugimura, T.; Okuyama, T. Tetrahedron Lett. 2007, 48, 8691-8694. doi:10.1016/j.tetlet.2007.10.015

37. Uyanik, M.; Yasui, T.; Ishihara, K. Angew. Chem., Int. Ed. 2010, 49, 2175-2177. doi:10.1002/anie.200907352

38. Uyanik, M.; Yasui, T.; Ishihara, Y. K. Tetrahedron 2010, 66, 5841-5851. doi:10.1016/j.tet.2010.04.060

39. Uyanik, M.; Yasui, T.; Ishihara, K. Angew. Chem., Int. Ed. 2013, 52, 9215-9218. doi:10.1002/anie.201303559 
40. Jain, N.; Xu, S.; Ciufolini, M. A. Chem. - Eur. J. 2017, 23, 4542-4546. doi:10.1002/chem.201700667

41. Quideau, S.; Lyvinec, G.; Marguerit, M.; Bathany, K.; Ozanne-Beaudenon, A.; Buffeteau, T.; Cavagnat, D.; Chénedé, A. Angew. Chem., Int. Ed. 2009, 48, 4605-4609. doi:10.1002/anie.200901039

42. Bosset, C.; Coffinier, R.; Peixoto, P. A.; El Assal, M.; Miqueu, K.; Sotiropoulos, J.-M.; Pouységu, L.; Quideau, S. Angew. Chem., Int. Ed. 2014, 53, 9860-9864. doi:10.1002/anie.201403571

43. Fujita, M.; Yoshida, Y.; Miyata, K.; Wakisaka, A.; Sugimura, T. Angew. Chem., Int. Ed. 2010, 49, 7068-7071. doi:10.1002/anie.201003503

44. Wirth, T. Angew. Chem., Int. Ed. Engl. 1995, 34, 1726-1728. doi:10.1002/anie.199517261

45. Wirth, T.; Hirt, U. H. Tetrahedron: Asymmetry 1997, 8, 23-26. doi:10.1016/S0957-4166(96)00469-7

46. Hirt, U. H.; Spingler, B.; Wirth, T. J. Org. Chem. 1998, 63, 7674-7679. doi:10.1021/jo980475x

47. Hirt, U. H.; Schuster, M. F. H.; French, A. N.; Wiest, O. G.; Wirth, T. Eur. J. Org. Chem. 2001, 1569-1579. doi:10.1002/1099-0690(200104)2001:8<1569::AID-EJOC1569>3.0.CO ;2-T

48. Fujita, M.; Wakita, M.; Sugimura, T. Chem. Commun. 2011, 47, 3983-3985. doi:10.1039/c1cc10129c

49. Shimogaki, M.; Fujita, M.; Sugimura, T. Angew. Chem., Int. Ed. 2016, 55, 15797-15801. doi:10.1002/anie.201609110

50. Röben, C.; Souto, J. A.; González, Y.; Lischynskyi, A.; Muñiz, K. Angew. Chem., Int. Ed. 2011, 50, 9478-9482. doi:10.1002/anie.201103077

51. Richardson, R. D.; Desaize, M.; Wirth, T. Chem. - Eur. J. 2007, 13, 6745-6754. doi:10.1002/chem.200700306

52. Farid, U.; Wirth, T. Angew. Chem., Int. Ed. 2012, 51, 3462-3465. doi:10.1002/anie.201107703

53. Kong, W.; Feige, P.; de Haro, T.; Nevado, C. Angew. Chem., Int. Ed. 2013, 52, 2469-2473. doi:10.1002/anie.201208471

54. Banik, S. M.; Medley, J. W.; Jacobsen, E. N. Science 2016, 353, 51-54. doi:10.1126/science.aaf8078

55. Banik, S. M.; Medley, J. W.; Jacobsen, E. N. J. Am. Chem. Soc. 2016, 138, 5000-5003. doi:10.1021/jacs.6b02391

56. Woerly, E. M.; Banik, S. M.; Jacobsen, E. N. J. Am. Chem. Soc. 2016, 138, 13858-13861. doi:10.1021/jacs.6b09499

57. Farid, U.; Malmedy, F.; Claveau, R.; Albers, L.; Wirth, T. Angew. Chem., Int. Ed. 2013, 52, 7018-7022. doi:10.1002/anie.201302358

58. For a racemic version of the same rearrangement: Moriarty, R. M.; Khosrowshahi, J. S.; Parakash, O. Tetrahedron Lett. 1985, 26 , 2961-2964. doi:10.1016/S0040-4039(00)98592-7.

59. Brown, M.; Kumar, R.; Rehbein, J.; Wirth, T. Chem. - Eur. J. 2016, 22, 4030-4035. doi:10.1002/chem.201504844

60. Qurban, J.; Elsherbini, M.; Wirth, T. J. Org. Chem. 2017, 82, 11872-11876. doi:10.1021/acs.joc.7b01571

61. Dong, D.-Q.; Hao, S.-H.; Wang, Z.-L.; Chen, C. Org. Biomol. Chem. 2014, 12, 4278-4289. doi:10.1039/c4ob00318g

62. Ochiai, M.; Takaoka, Y.; Masaki, Y.; Nagao, Y.; Shiro, M. J. Am. Chem. Soc. 1990, 112, 5677-5678. doi:10.1021/ja00170a063

63. Ochiai, M.; Kitagawa, Y.; Takayama, N.; Takaoka, Y.; Shiro, M. J. Am. Chem. Soc. 1999, 121, 9233-9234. doi:10.1021/ja992236c

64. Jalalian, N.; Olofsson, B. Tetrahedron 2010, 66, 5793-5800. doi:10.1016/j.tet.2010.05.004
65. Brown, M.; Delorme, M.; Malmedy, F.; Malmgren, J.; Olofsson, B.; Wirth, T. Synlett 2015, 26, 1573-1577. doi:10.1055/s-0034-1380687

66. Altermann, S. M.; Richardson, R. D.; Page, T. K.; Schmidt, R. K.; Holland, E.; Mohammed, U.; Paradine, S. M.; French, A. N.; Richter, C.; Bahar, A. M.; Witulski, B.; Wirth, T. Eur. J. Org. Chem. 2008, 5315-5328. doi:10.1002/ejoc.200800741

67. Brenet, S.; Berthiol, F.; Einhorn, J. Eur. J. Org. Chem. 2013, 8094-8096. doi:10.1002/ejoc.201301329

68. Mizar, P.; Wirth, T. Angew. Chem., Int. Ed. 2014, 53, 5993-5997. doi:10.1002/anie.201400405

69. Uyanik, M.; Okamoto, H.; Yasui, T.; Ishihara, K. Science 2010, 328, 1376-1379. doi:10.1126/science.1188217

70. Wu, H.; He, Y.-P.; Xu, L.; Zhang, D.-Y.; Gong, L.-Z. Angew. Chem., Int. Ed. 2014, 53, 3466-3469. doi:10.1002/anie.201309967

71. Cao, Y.; Zhang, X.; Lin, G.; Zhang-Negrerie, D.; Du, Y. Org. Lett. 2016, 18, 5580-5583. doi:10.1021/acs.orglett.6b02816

72. Levitre, G.; Dumoulin, A.; Retailleau, P.; Panossian, A.; Leroux, F. R.; Masson, G. J. Org. Chem. 2017, 82, 11877-11883. doi:10.1021/acs.joc.7b01597

73. Suzuki, S.; Kamo, T.; Fukushi, K.; Hiramatsu, T.; Tokunaga, E.; Dohi, T.; Kita, Y.; Shibata, N. Chem. Sci. 2014, 5, 2754-2760. doi:10.1039/C3SC53107D

74. Fernández González, D.; Brand, J. P.; Mondière, R.; Waser, J. Adv. Synth. Catal. 2013, 355, 1631-1639. doi:10.1002/adsc.201300266

75. Fernández González, D.; Brand, J. P.; Waser, J. Chem. - Eur. J. 2010, 16, 9457-9461. doi:10.1002/chem.201001539

76. Wu, X.; Shirakawa, S.; Maruoka, K. Org. Biomol. Chem. 2014, 12, 5388-5392. doi:10.1039/C4OB00969J

77. Companys, S.; Peixoto, P. A.; Bosset, C.; Chassaing, S.; Miqueu, K.; Sotiropoulos, J.-M.; Pouységu, L.; Quideau, S. Chem. - Eur. J. 2017, 23, 13309-13313. doi:10.1002/chem.201703238

\section{License and Terms}

This is an Open Access article under the terms of the Creative Commons Attribution License (http://creativecommons.org/licenses/by/4.0), which permits unrestricted use, distribution, and reproduction in any medium, provided the original work is properly cited.

The license is subject to the Beilstein Journal of Organic Chemistry terms and conditions: (https://www.beilstein-journals.org/bjoc)

The definitive version of this article is the electronic one which can be found at: doi:10.3762/bjoc.14.107 